\title{
Acknowledgments to the Second Edition
}

Such an undertaking requires the support and cooperation of numerous colleagues. We imposed on several friends and colleagues to review the chapters from the original edition and solicited their input to determine what, and how much, new information should be included in the new edition. Many of these "preliminary reviewers" were extremely helpful and supplied reprints or unpublished data that we incorporated into the text. After we had completed our revisions, we sent the chapters back to the same reviewers and invited their comments on the readability and accuracy of our revisions. Without the patience and dedication of those reviewers, this revision would undoubtedly be less complete and accurate.

We feel that all these revisions further strengthen a text that already had come to be recognized as "the bible of turfgrass entomology." We are indebted to Dr. Haruo Tashiro, who had the perseverance to complete the massive undertaking of preparing the first edition. His style and organizational plan worked very well, and we have endeavored to preserve it as much as possible.

The chapter reviewers included Steven R. Alm, University of Rhode Island, Kingston; Arthur L. Antonelli, Western Washington Research and Extension Center, Puyallup; Frederick P. Baxendale, University of Nebraska-Lincoln; S. Kris Braman, University of Georgia, Griffin; Rick L. Brandenburg, North Carolina State University, Raleigh; Patricia P. Cobb, Auburn University, Auburn, Alabama; Rich S. Cowles, Connecticut Agricultural Experiment Station, Windsor; Whitney S. Cranshaw, Colorado State University, Fort Collins; Robert L. Crocker, Texas A\&M Agricultural and Extension Center, Dallas; Bastiaan M. Drees, Texas A\&M Extension, Bryan; Roch Gaussoin, University of NebraskaLincoln; Wendy Gelernter, Pace Consulting, San Diego, California; Timothy J. Gibb, Purdue University, West Lafayette, Indiana; Arnold H. Hara, University of Hawai'i, Honolulu; Paul R. Heller, Pennsylvania State University, University Park; Will G. Hudson, University of Georgia, Tifton; Richard Hull, University of Rhode Island, Kingston; Albert W. Johnson, Clemson University, Florence, South Carolina; Jennifer M. JohnsonCicalese, New Brunswick, New Jersey; Michael G. Klein, USDA Japanese Beetle Laboratory, Wooster, Ohio; Daniel A. Potter, University of Kentucky, Lexington; James A. Reinert, Texas A\&M Agricultural and Extension Center, Dallas; Paul S. Robbins, New 
York State Agricultural Experiment Station, Geneva; Frank Rossi, Cornell University, Ithaca, New York; David J. Shetlar, Ohio State University, Columbus; David R. Smitley, Michigan State University, East Lansing; Gwen Stahnke, Washington State University, Puyallup; Stanley R. Swier, University of New Hampshire, Durham; Mike P. Tolley, Dow Elanco, Indianapolis, Indiana; and R. Chris Williamson, TrueGreen-ChemLawn, Columbus, Ohio.

Several of these individuals were extraordinarily helpful: Fred Baxendale and Pat Cobb reviewed several chapters on short notice; Dave Shetlar provided tremendous input in the webworm, cutworm, and billbug sections (Chapters 8, 9, and 18); Dan Potter reviewed all the grub chapters and provided valuable insight on reorganizing those chapters (Chapters 11-16); Jennifer Johnson-Cicalese provided volumes of material and suggested revisions for the billbug section (Chapter 18); and Bart Drees was invaluable in revising the ant section (Chapter 20).

One of the strengths of the original edition was the quality and quantity of full-color plates. We have expanded our commitment to color photography, and this edition includes 72 full-color plates, presented in a visually pleasing manner. The color plates in the first edition have proved very useful to turf managers as they attempted to identify insect pests in the field, and we felt further expansion was appropriate. This has enabled us to include some of the beneficial organisms and biological control agents, as well as examples of sampling techniques.

Just as "Tash" noted in the first edition, we too are indebted to the many people, including some who were also reviewers, who have freely provided us with color transparencies to be included in this edition or insect specimens which were then photographed at the New York State Agricultural Experiment Station (NYSAES) in Geneva. Those contributors include W. F. Berliner, G. C. Hickman, L. L. Masters, and T. Yates, all from the American Society of Mammalogists Mammal Slide Library; Arthur L. Antonelli; Frederick P. Baxendale; Rick L. Brandenburg; Leland R. Brown, University of California, Riverside; R. Scott Cameron, Texas Forest Service, Lufkin; Patricia P. Cobb; Sharon J. Collman, Cooperative Extension Service, Seattle, Washington; Cornell University Laboratory of Ornithology; Robert L. Crocker; David N. Ferro, University of Massachusetts-Amherst; Ken Gray Slide Collection, Oregon State University, Corvallis; M. P. Johnson (courtesy of Daniel A. Potter); James Kalisch, University of Nebraska-Lincoln; Michael G. Klein; Jeffrey Kollenkark; C. Kouskolekas, Auburn University, Auburn, Alabama; W. Mesner (courtesy of Daniel A. Potter); Charles M. Murdoch, University of Hawai'i, Honolulu; Harry D. Niemczyk, Ohio Agricultural Research and Development Center, Wooster; Asher K. Ota, Hawaii Sugar Planters' Association, Aiea; F. B. Peairs; Michael F. Potter and Daniel A. Potter, University of Kentucky, Lexington; Roy W. Rings, Ohio Agricultural Research and Development Center, Wooster; Mark K. Sears, University of Guelph, Guelph, Ontario, Canada; David J. Shetlar; Herbert T. Streu, Rutgers University, New Brunswick, New Jersey; Mike P. Tolley; D. M. Tsuda, University of Hawai'i, Honolulu; and Louis M. Vasvary (Rutgers University, New Brunswick, New Jersey).

Several new figures and sketches were incorporated into this second edition, including many that were drawn by Robert Jarecke (NYSAES) and first appeared in the Hand- 
book of Turfgrass Insect Pests (R. L. Brandenburg and M. G. Villani, editors, 1995), published by the Entomological Society of America (ESA), Lanham, Maryland. We are indebted to the ESA and to "RJ" for granting us permission to reproduce those sketches and distribution maps. In addition, RJ provided several new figures, including sketches of the life stages of the fiery skipper and the European crane fly (Figures 10-2 and 19-2) and the lacinia of southern and tawny mole crickets (Figure 5-3). Terrency McSharry (University of Massachusetts-Amherst) provided three new sketches: turf profile (Figure 3-1), sexual dimorphism in masked chafers (Figure 14-3), and a Berlese funnel (Figure 26-3).

Many of the photographic and illustrative services for NYSAES, and for this book in particular, were provided by Joseph Ogrodnick and Robert Way. Rob Way worked indefatigably with Haruo Tashiro to arrange and lay out the color plates. Many of the blackand-white diagrams were drawn by Rose McMillen-Sticht and Haruo Tashiro for the first edition and were retained in this edition because of their clarity of presentation.

Special thanks go to Daniel Potter and Dave Shetlar, who reviewed the entire text before we began our revisions. Their suggestions, particularly regarding overall organization, proved invaluable. In addition, Dr. Rick Brandenburg read through the entire revision, double-checking for accuracy of figure or plate numbers, references, readability, consistency, and accuracy of text. Without their efforts, this edition would undoubtedly be much less complete and polished. 
